\section{Retinopathy of prematurity in South Africans at a tertiary hospital: a prospective study}

I Mayet and C Cockinos

\begin{abstract}
Background and Objectives World Health Organization's vision 20/20 programme has recognized retinopathy of prematurity (ROP) as an important cause of childhood blindness in industrialized and middle-income countries. While ROP is virtually nonexistent in many African countries, ROP is seen in urban areas where facilities for neonatal care exist. The aim of this study is to establish the frequency of ROP in a cohort of patients screened for ROP and to establish if current screening criteria apply to our patients.

Patients and Methods Infants with birth weight (BW) of $1500 \mathrm{~g}$ or less and/or gestational age of 32 weeks or less were screened for ROP over a $2 \frac{1}{2}-$ year period by a single examiner.

Results ROP was observed in 84 of 514 (16.3\%) of infants included for analysis.

Threshold disease (tROP) was noted in $1.6 \%$ of the total cohort although $41 / 84$ babies with ROP were lost prior to regression or progression to tROP. Of the $43 / 84$ adequately followed up, eight (18.6\%) developed tROP. An estimated frequency of tROP was more likely to be $2.9 \%$. There was no $t R O P$ noted in babies of BW greater than $1250 \mathrm{~g}$. Gestational age was an unreliable risk parameter in our population.

Conclusion The projected occurrence rate of tROP is similar to that found in black

Introduction

Retinopathy of prematurity (ROP) is a vasoproliferative disorder affecting the retina of premature babies. The World Health Organization Vision 20/20 programme has identified ROP as an important cause of blindness in countries with low infant mortality rates. ${ }^{1}$ Studies suggest that ROP is more prevalent in very low birth weight (BW) neonates (infants $<1000 \mathrm{~g}$ ) in industrialized countries and is emerging as a major cause of childhood blindness ${ }^{2}$ in middle-income countries such as those in Latin America, Asia, and Eastern Europe.

In Africa, where preventable diseases of the cornea such measles and avitaminosis are the major causes of blindness in childhood, retinal pathology accounts for a minority of childhood blindness. ROP as a cause of blindness is negligible. ${ }^{3,4}$ Wheatley et $a l^{5}$ have suggested a low incidence of ROP in Africa is due to high infant mortality rates and lack of intensive care facilities. However, ROP is not uncommon in urban centres in South Africa where neonatal care facilities do exist. ${ }^{6,7}$ As a follow-up to previous small studies, we conducted large prospective study of ROP at Chris Hani Baragwanath Hospital (CHBH), Soweto, a tertiary referral centre for indigent South African patients. The aim of the study was to establish the occurrence rate or frequency of ROP and possible risk factors, and to thereby establish an efficient screening programme for ROP in our population.
\end{abstract} population in the Multicentre Cryotherapy for ROP Trial. Our data suggest that the screening criterion based on BW can safely be lowered to $1250 \mathrm{~g}$ in our population.

Eye (2006) 20, 29-31. doi:10.1038/sj.eye.6701779; published online 21 January 2005

Keywords: retinopathy of prematurity; Africa

\section{Patients and methods}

A prospective study of ROP in all premature neonates born before 32 weeks gestation and/or birth weight $<1500 \mathrm{~g}$ was undertaken. All of the babies were seen in the neonatal unit at $\mathrm{CHBH}$
Department of

Ophthalmology, Chris Hani Baragwanath Hospital and University of the Witwatersrand,

Johannesburg, South Africa

Correspondence: Dr I Mayet Department of

Ophthalmology, University of the Witwatersrand, Witwatersrand Medical School, 1 York Road, Parktown 2190, Johannesburg, South Africa Tel: + 2711728 3289; Fax: + 27117286839 . E-mail: eyemay@ absamail.co.za

Received: 1 August 2004 Accepted: 21 October 2004 Published online: 21 January 2005 
during the period July 2001-December 2003. Of the 48589 live births during this period, 532 met the Royal College of Ophthalmology guidelines for ROP screening. ${ }^{8}$ Except for six Caucasian neonates, all the patients were of black race. Only the latter group of 526 neonates was included in the analysis.

Initial examination was conducted 3-7 weeks postnatally in a recovery ward following the infant's discharge from the neonatal intensive care unit. All the babies were screened for ROP by a single ophthalmologist (IM). Pupillary dilatation was achieved using cyclopentolate $2.5 \%$ and phenylephrine $0.5 \%$ combination drops. Retinal changes were classified according to the most advanced stage of ROP reached using the International Classification of ROP. ${ }^{9}$ If vascularization was incomplete, babies were seen 2weekly intervals while those with ROP were seen at weekly intervals until regression or threshold ROP disease (tROP) was noted. Babies with tROP disease were treated with cryotherapy.

The following clinical parameters were recorded: BW, gestational age (GA), gender, single or multiple births, stage of ROP, and progression of ROP. In the majority of cases, GA was unreliable in assessing prematurity because many of the mothers neither could recall their last menses, nor have early antenatal ultrasound examinations. Often the extent of peripheral retinal vascularization was more extensive than expected for the GA recorded in the hospital files.

\section{Statistical methods}

Data were analysed using Statistica 5.1[. STAT-SOFT INC.(1998).Statistica for Windows].

\section{Results}

Of the 526 neonates, 50 were from multiple births and 476 were singleton births. There were 273 female and 253 male neonates. The mean age at examination was 35.1 weeks $(\mathrm{SD} \pm 3.7)$. A breakdown of $\mathrm{BW}$ is shown in Figure 1. The mean GA was 30.4 weeks $(\mathrm{SD} \pm 2.4)$.

In total, 12 babies were lost to follow-up before evidence of complete vascularization or ROP could be noted. Of the 514 remaining babies, 84 (16.3\%) were noted to have ROP. Of those with ROP, 41 were lost to follow-up prior to witnessing regression or progression to tROP. Of the remaining 43 babies with ROP, eight (18.6\%) developed tROP necessitating treatment and 35 showed regression. The overall occurrence rate of stage 3 disease was $2.5 \%$ while those with tROP requiring treatment, represented $1.6 \%$ of the total cohort. No tROP was observed in neonates of BW greater than $1250 \mathrm{~g}$.

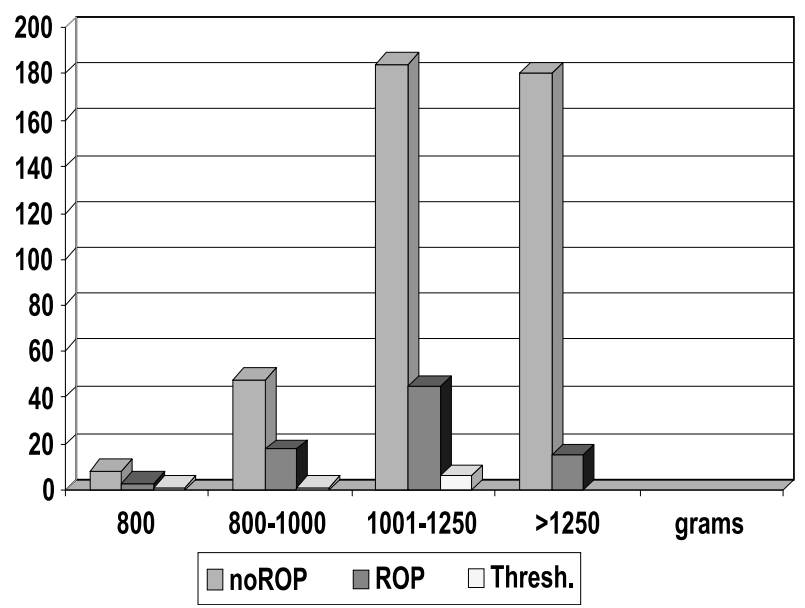

Figure 1 Distribution of babies screened according to BW.

Of the eight treated babies, one died 2 weeks posttreatment, two were lost to follow-up, four showed regression and one progressed to retinal detachment - the only neonate with ROP involving Zone 1.

Using univariate analysis the mean BW of neonates with ROP was significantly lower, 1093.7g (SD \pm 173.2), compared to $1215.6 \mathrm{~g}(\mathrm{SD} \pm 174.6)$ in neonates without ROP $(P<0.0005)$. Multiple births did not influence the risk of developing ROP.

\section{Discussion}

In developed countries, there appears to be a 'lull' in the incidence of ROP with only the very low birth infants being affected. ${ }^{10}$ The incidence of childhood blindness, due to ROP in certain Latin American and East European countries were as high as 38.6 and $25.9 \%$, respectively. ${ }^{2}$ The incidence of ROP in a Vietnamese study ${ }^{11}$ was $45.8 \%$ in neonates less than $2000 \mathrm{~g}$ and $81.2 \%$ in babies less than $1250 \mathrm{~g}$. In total, $25 \%$ of the babies $<1250 \mathrm{~g}$ developed tROP.

Very little is known about the incidence of ROP in subSaharan Africa, information which is important if we are to plan screening and treatment strategies aimed at preventing blindness in childhood in Africa.

From an early study of children in blind schools in South Africa $10.6 \%{ }^{6}$ were due to ROP and of this only $1.25 \%$ were of black population.

Kirsten et $\mathrm{l}^{6}$ reported a 30\% frequency of ROP and 7\% with stage 3 or worse, although the population considered was multiracial.

Delport $e t a l^{7}$ reported a frequency of $24.5 \%$ of ROP in a black hospital with $6.4 \%$ developing stage 3 disease and $4.2 \%$ required treatment (including one neonate with $\mathrm{BW}$ only $>1250 \mathrm{~g}$ ). 
Our study shows a lower frequency of ROP (16.3\%) and of tROP $(1.6 \%)$. The frequency of tROP may be an underestimation because almost half of ROP patients were lost to follow-up. If we suppose that $18.6 \%$ of these could have developed tROP another seven patients would have progressed to tROP. This would reflect a frequency of $2.9 \%$ of tROP, which is very similar to that of black infants in the Cryotherapy-ROP trial ${ }^{12}$ (3.2\%).

We also concur with Delport $e t a l^{7}$ that GA is not a reliable factor in assessing risk for ROP in our population.

In the Cryotherapy-ROP Trial, ${ }^{12}$ only babies with BWs of less than $1251 \mathrm{~g}$ were included. While we adopt the Royal College Recommendations of screening infants less than $1500 \mathrm{~g}$, we are in agreement with studies ${ }^{13-15}$ that recommend lowering the $\mathrm{BW}$ criterion for screening infants for ROP to $1250 \mathrm{~g}$. None of our patients over $1250 \mathrm{~g}$ developed tROP. This would have decreased the number of babies screened by $38 \%$ in our study. This is especially relevant to Africa where screening facilities may be limited.

While comparison between different racial groups was not possible in our study due to the small number of light coloured fundi, this study supports the findings of other studies $^{16-18}$ regarding the low occurrence rate of ROP especially of advanced disease in black patients or darkly pigmented fundi.

Genetic factors as hypothesized by Flynn ${ }^{19}$ still remain to be established while the role of RPE as suggested by Cryo-ROP Cooperative Group ${ }^{16}$ appears to be important. While melanin has been suggested as a logical protector, ${ }^{18}$ it is tempting to postulate a role of pigment epithelium-derived factor (PEDF) in blocking the action of vaso-endothelial growth factor (VEGF) or on insulin like growth factor (IGF), both of which are important in the proliferative phase of the disease as shown by Smith $^{20}$ in animal models. This would imply that darker fundi have a greater concentration of PEDF, which to the best of our knowledge has not been shown.

Our study has inherent shortfalls characteristic of many studies from Africa, namely the large number of patients that are lost to follow-up. However, we believe that despite this limitation it is important to qhave this information to guide us in screening for ROP in Africa.

\section{Acknowledgements}

We thank the nursing staff of St John Eye Hospital for their ongoing assistance in screening, Professor M Tikly for assistance in analysing our stats, and Dr Velapi of the neonatal intensive care unit at $\mathrm{CHBH}$ for accommodating us.

\section{References}

1 Gilbert C, Foster A. Childhood blindness in the context of Vision 20/20 - the right to sight. Bull World Health Organisation 2001; 79: 227-232.

2 Gilbert C, Rahi J, Eckstein M, O'Sullivan J, Foster A. Retinopathy of prematurity in middle income countries. Lancet 1997; 350: 12-14.

3 Kello C, Gilbert AB. Causes of severe visual impairment and blindness in children in schools for the blind in Ethopia. Br J Ophthalmol 2003; 87: 526-530.

4 O'Sullivan J, Gilbert C, Foster A. The causes of childhood blindness South Africa. S Afr Med J 1997; 87(12): 1691-1695.

5 Wheatley CM, Dickinson JL, Mackay DA, Craig JE, Sale MM. Perspective - Retinopathy of Prematurity: recent advances in our understanding. Br J Ophthalmol 2002; 86: 696-701.

6 Kirsten GF, van Zyl JI, le Grange M, Anker E, van Zyl F. The outcome of very low birthweight infants ventilated at Tygerberg Hospital. S Afr Med J 1995; 85(7): 649-654.

7 Delport S, Swanepoel JC, Odendaal P, Roux P. Incidence of retinopathy of prematurity in very low birth weight infants born at the Kalafong Hospital, Pretoria. S Afr Med J 2002; 92(12): 986-990.

8 Royal College of Ophthalmology and British Association of Perinatal Medicine. Retinopathy of Prematurity: Guidelines for Screening and Treatment. The report of a joint working party 1995.

9 Committee for the classification of Retinopathy of Prematurity. An International Classification of Retinopathy of Prematurity. Arch Ophthalmol 1984; 102: 1130-1134.

10 Gilbert C. Editorial - Retinopathy of prematurity-The 'second lull'? Br J Ophthalmol 2001; 85: 1017-1019.

11 Phan MH, Nguyen PN, Reynolds JD. Incidence and severity of retinopathy of prematurity in Vietnam, a developing middle income country. J Pediatr Ophthalmic Strabismus 2003; 40(4): 208-212.

12 Cryotherapy for Retinopathy of Prematurity Cooperative Group. Incidence and early course of retinopathy of prematurity. Ophthalmology 1991; 98(11): 1628-1639.

13 Fleck BW, Wright E, Dhillon B, Millar GT, Laing LA. An Audit of the 1995 Royal College of Ophthalmology Guidelines for the Screening of Retinopathy of Prematurity applied retrospectively in one regional Neonatal ICU. Eye 1995; 9(Suppl. 6): 31-35.

14 Gobble RR, Jones HS, Fielder AR. Are we screening too many babies for retinopathy of prematurity? Eye 1997; 11(4): 509-514.

15 Mathew MRK, Fern AI, Hill R. Retinopathy of prematurity: are we screening too many babies? Eye 2002; 16(5): 538-542.

16 Cryotherapy for Retinopathy of prematurity Cooperative Group. Racial variation in retinopathy of prematurity. Arch Ophthalmol 1997; 115: 604-608.

17 Fielder AR, Shaw DE, Robinson J, Ng YK. Natural history of retinopathy of prematurity: a prospective study. Eye 1992; 6(3): 233-242.

18 Monos T, Rosen SD, Karplus M, Yassur Y. Fundus pigmentation in retinopathy of prematurity. Pediatrics 1996; 97(3): 343-348.

19 Flynn JT. The premature retina: a model for the in vivo study of molecular genetics. Eye 1992; 6(2): 161-165.

20 Smith LEH. Pathogenesis of retinopathy of prematurity. Acta Paediatr Suppl 2002; 437: 26-28. 